\title{
Corneocytes: Relationship between Structural and Biomechanical Properties
}

\author{
Ana S. Évora Michael J. Adams Simon A. Johnson Zhibing Zhang \\ School of Chemical Engineering, University of Birmingham, Birmingham, UK
}

\section{Keywords}

Corneocyte · Skin · Stratum corneum · Mechanical properties $\cdot$ Corneodesmosomes $\cdot$ Cornified envelope

\begin{abstract}
Background: Skin is the interface between an organism and the external environment, and hence the stratum corneum (SC) is the first to withstand mechanical insults that, in certain conditions, may lead to integrity loss and the development of pressure ulcers. The SC comprises corneocytes, which are vital elements to its barrier function. These cells are differentiated dead keratinocytes, without organelles, composed of a cornified envelope and a keratin-filled interior, and connected by corneodesmosomes (CDs). Summary: The current review focusses on the relationship between the morphological, structural, and topographical features of corneocytes and their mechanical properties, to understand how they assist the SC in maintaining skin integrity and in responding to mechanical insults. Key Messages: Corneocytes create distinct regions in the SC: the inner SC is characterized by immature cells with a fragile cornified envelope and a uniform distribution of CDs; the upper $\mathrm{SC}$ has resilient cornified envelopes and a honeycomb distribution of CDs, with a greater surface area and a smaller thickness than cells from the inner layer. The literature indicates that this upward maturation process is one of the most important steps in the mechanical resistance and barrier function of the SC. The
\end{abstract}

(C) 2021 S. Karger AG, Basel

www.karger.com/spp

Karger ${ }^{\prime}=$ morphology of these cells is dependent on the body site: the surface area in non-exposed skin is about 1,000-1,200 $\mu^{2}$, while for exposed skin, for example, the cheek and forehead, is about $700-800 \mu \mathrm{m}^{2}$. Corneocytes are stiff cells compared to other cellular types, for example, the Young's modulus of muscle and fibroblast cells is typically a few $\mathrm{kPa}$, while that of corneocytes is reported to be about hundreds of MPa. Moreover, these skin cells have 2 distinct mechanical regions: the cornified envelope (100-250 MPa) and the keratin matrix (250-500 MPa).

(c) 2021 S. Karger AG, Basel

\section{Introduction}

Human skin is composed of 3 main dynamic layers, namely, the hypodermis, dermis, and epidermis [1]. The latter is the outermost layer (Fig. 1), being a waterproof barrier protecting the organism against the entry of foreign bodies and physical and mechanical insults [2]. It is a stratified and squamous epithelium that can be subdivided into 4 discrete layers, in which keratinocytes, the main cell type, undergo a differentiation process, from the inner layer, at the epidermal-dermal interface (stratum germinativum or basal cell layer), to the stratum corneum (SC) $[3,4]$. The SC is usually described by a "bricks and mortar" structural model [5] (Fig. 2) where the corneocytes are completely flattened and their keratin-filled interior is surrounded by 
Fig. 1. Schematic diagram of the epidermis: keratinocytes proliferate in the basal cell layer and move upwards in the stratum spinosum where they start to suffer a differentiation process while migrating upwards in the epidermis. This process involves a synthesizing step in the stratum granulosum and culminates with death by cornification and maturation of corneocytes in the outermost layer of the SC. SC, stratum corneum.

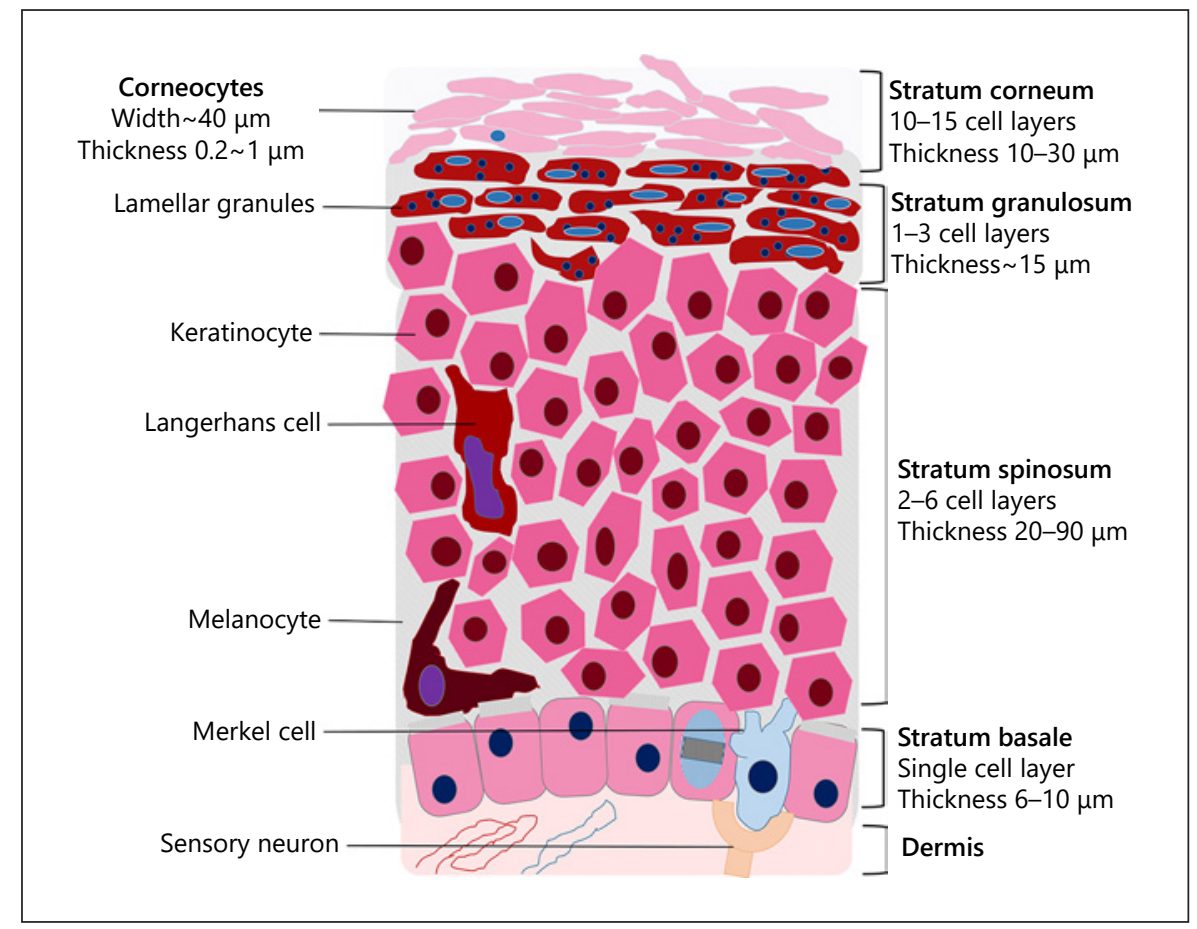

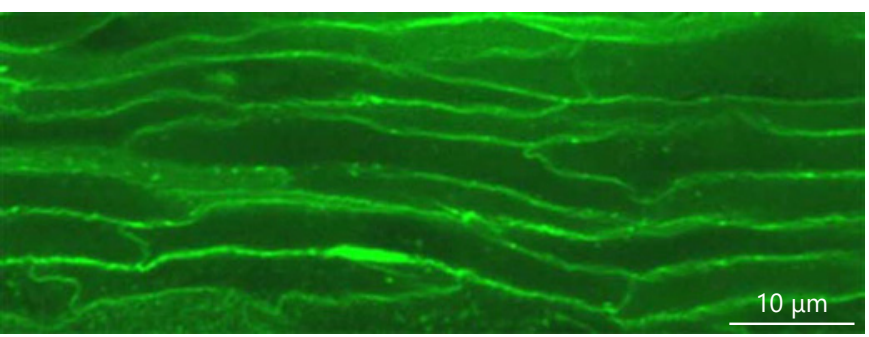

Fig. 2. Confocal fluorescence images after staining with Nile red in alkali solution to swell the corneocytes in order to render them visible in an optical microscope (cells are expanded by a factor of 5 in the thickness dimension). The specimen was mechanically and optically cross-sectioned in the same apical-to-basal plane, dorsum skin. The image illustrates the "bricks and mortar" structure of the SC. Reproduced, with permission, from Talreja et al. [5]. SC, stratum corneum.

protein and lipid envelopes (cornified envelopes and cornified lipid envelopes, CEs and CLEs, respectively) [6]. Adjacent corneocytes are connected by corneodesmosomes (CDs) for which localization and density depend on the depth of localization of the cells in the SC [7]. Intercellular lamellae of lipids, such as ceramides, cholesterol, and fatty acids, are first synthesized in the stratum granulosum [6] and compose the "mortar" of the SC.

The SC functions as a barrier between the organism and the external environment, being responsible for the control of trans-epidermal water loss (TEWL) and the selective absorption of compounds [8]. The thickness of the SC varies depending on the body site - that of the cheek and back of the hand being 17 and $30 \mu \mathrm{m}$, respectively, while that from the palm being much thicker $(173 \mu \mathrm{m})[9]-$ although this will vary somewhat for different individuals. The complex hierarchical structure of the SC has 2 main functions: while corneocytes and CDs mainly contribute to the mechanical resistance of the layer, the intercellular lipids are mainly involved in the barrier function [10], preventing water loss and the entry of foreign bodies. The mechanical resistance of the skin to environmental insults is a critical function of the structural cohesion of the SC and the mechanical resilience of the corneocytes, which depends on the differentiation process of the keratinocytes in the epidermis.

There are several reviews on the composition and biochemistry of the SC that mainly reveal the mechanisms underlying its barrier function in healthy skin and several disorders [11-13]. However, the mechanical function of the SC has been addressed in less detail. Many studies have examined the pathways leading to the loss of skin integrity under the action of applied stresses, but there is still not a consensus on the underlying mechanisms. The current review aims to consider the relationship between the structure and morphology of corneocytes and their biomechanical properties since these dead cells are the first elements to sense load and friction. 
Table 1. Surface area of corneocytes from different body sites, ages, and genders

\begin{tabular}{|c|c|c|c|c|c|}
\hline \multicolumn{6}{|c|}{ Surface area, $\mu \mathrm{m}^{2}$} \\
\hline body region & babies & children & adults & & aged \\
\hline \multirow[t]{2}{*}{ Scalp } & \multirow[t]{2}{*}{$\sim 700[16]$} & \multirow[t]{2}{*}{$\sim 800[16]$} & Male & $\sim 900[16,17]$ & \multirow{2}{*}{$1,000[16]$} \\
\hline & & & Female & $\sim 1,100[16,17]$ & \\
\hline \multirow[t]{2}{*}{ Forehead } & \multirow[t]{2}{*}{$\sim 750[16]$} & \multirow[t]{2}{*}{$\sim 750[16]$} & Male & $\sim 750[16,17]$ & \multirow{2}{*}{$900[16]$} \\
\hline & & & Female & $\sim 900[16,17]$ & \\
\hline \multirow[t]{2}{*}{ Axilla } & \multirow[t]{2}{*}{$\sim 800[16]$} & \multirow[t]{2}{*}{$\sim 1,000[16]$} & Male & $\begin{array}{r}\sim 1,200[16,17] \\
1,148 \pm 11[19]\end{array}$ & \multirow{2}{*}{$1,400[16]$} \\
\hline & & & Female & $\begin{array}{r}\sim 1,250[16,17] \\
1,176 \pm 11[19]\end{array}$ & \\
\hline \multirow[t]{3}{*}{ Upper arm } & \multirow[t]{3}{*}{$\sim 800[16]$} & \multirow[t]{3}{*}{$\sim 1,000[16]$} & Male & $\begin{array}{r}\sim 1,000[16,17] \\
1,098 \pm 12[19]\end{array}$ & \multirow{3}{*}{$1,200[16]$} \\
\hline & & & Female & $\begin{array}{r}\sim 1,050[16,17] \\
1,145 \pm 14[19]\end{array}$ & \\
\hline & & & - & $\sim 1,000[20]$ & \\
\hline \multirow[t]{3}{*}{ Forearm } & \multirow[t]{3}{*}{$\sim 700[16]$} & \multirow[t]{3}{*}{$\sim 900[16]$} & Male & $\begin{array}{l}\sim 850[16,17] \\
1,004 \pm 12[19]\end{array}$ & \multirow{3}{*}{$\begin{array}{l}1,100[16] \\
\quad 753 \pm 120[22] \\
1,000-1,300[21]\end{array}$} \\
\hline & & & Female & $\begin{array}{r}\sim 1,100[16,17] \\
1,018 \pm 21[19]\end{array}$ & \\
\hline & & & $\begin{array}{l}- \\
- \\
- \\
-\end{array}$ & $\begin{array}{l}\sim 840[18] \\
555 \pm 80[22] \\
600-1,000[21] \\
1,000 \pm 200[24]\end{array}$ & \\
\hline \multirow[t]{2}{*}{ Hand } & \multirow[t]{2}{*}{$\sim 650[16]$} & \multirow[t]{2}{*}{$\sim 700[16]$} & Male & $\sim 800[16,17]$ & $\sim 1,000[16]$ \\
\hline & & & Female & $\begin{array}{l}\sim 1,000[16,17] \\
\quad 600-850[21]\end{array}$ & $800-1,050[21]$ \\
\hline \multirow[t]{2}{*}{ Abdomen } & \multirow[t]{2}{*}{$\sim 800[16]$} & \multirow[t]{2}{*}{$\sim 800[16]$} & Male & $\begin{array}{c}\sim 1,000[16,17] \\
\quad 1,130 \pm 8[19]\end{array}$ & \multirow[b]{2}{*}{$\sim 1,300[16]$} \\
\hline & & & Female & $\begin{array}{l}\sim 1,400[16,17] \\
1,180 \pm 18[19] \\
\sim 850[18]\end{array}$ & \\
\hline \multirow[t]{2}{*}{ Thigh } & \multirow[t]{2}{*}{$\sim 750[16]$} & \multirow[t]{2}{*}{$\sim 800[16]$} & Male & $\begin{array}{r}\sim 1,100[16,17] \\
1,184 \pm 17[19]\end{array}$ & \multirow{2}{*}{$-\sim 1,300[16]$} \\
\hline & & & Female & $\begin{array}{r}\sim 1,300[16,17] \\
1,188 \pm 14[19]\end{array}$ & \\
\hline \multirow[t]{2}{*}{ Heel } & \multirow[t]{2}{*}{-} & \multirow[t]{2}{*}{-} & Male & $\begin{array}{l}\sim 800[16,17] \\
1,104 \pm 12[19]\end{array}$ & \\
\hline & & & Female & $\begin{array}{r}\sim 1,000[16,17] \\
1,101 \pm 12[19]\end{array}$ & - \\
\hline Cheek & - & - & $\begin{array}{l}- \\
- \\
-\end{array}$ & $\begin{array}{l}\sim 680[20] \\
\quad 750 \pm 150[24] \\
800-1,000[20]\end{array}$ & - \\
\hline
\end{tabular}



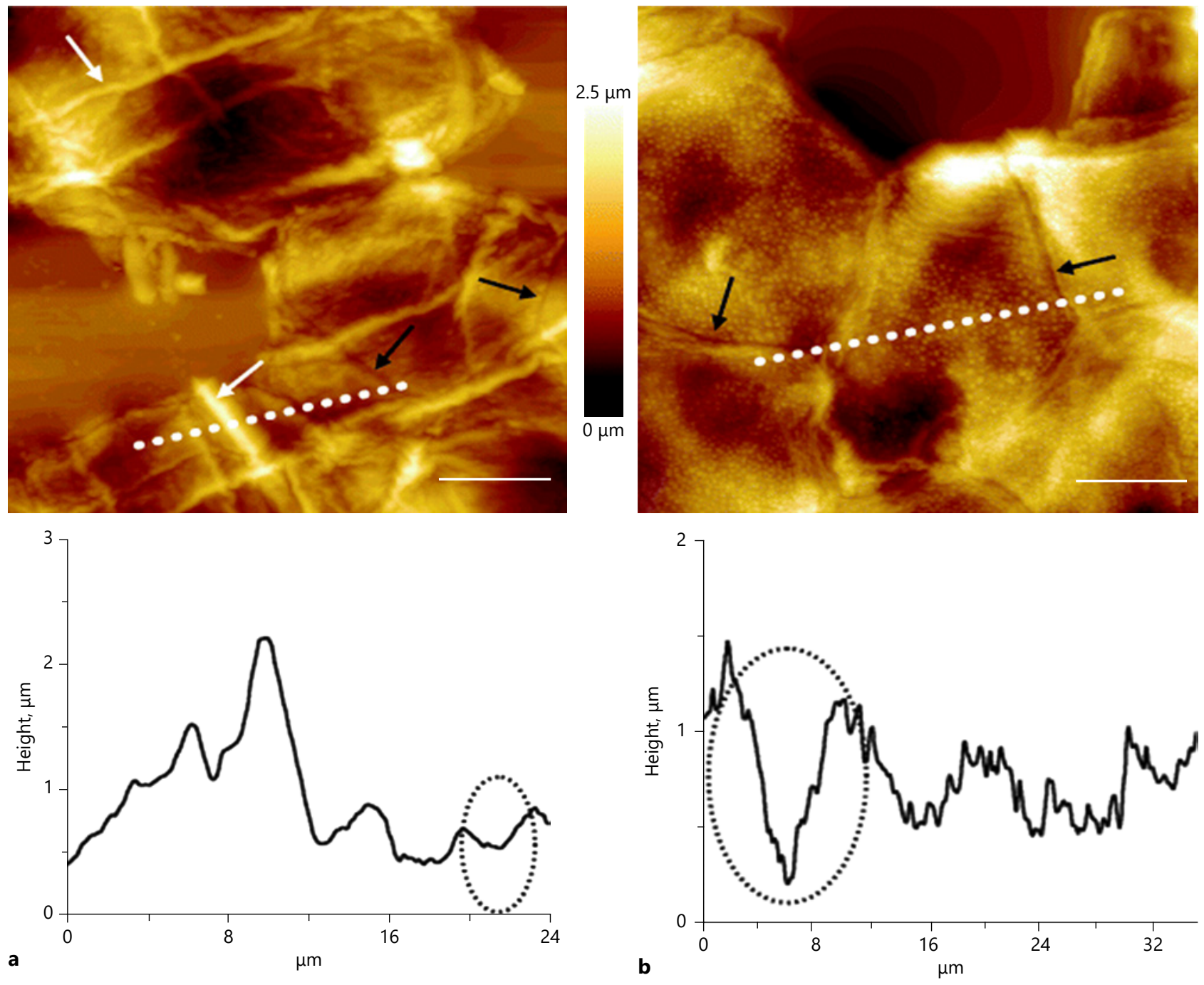

Fig. 3. 3D image of corneocytes from a young donor (a) and from an aged donor (b). Height is given in colour brightness - lateral dimension by scale bar $(10 \mu \mathrm{m})$. The white arrows point to filamentous structures so far unidentified, while the black arrow indicates cell-cell contacts between 2 corneocytes. The dotted line indicates a cross-section that is displayed below. The dotted circle indicates the intercellular gap. Reproduced with permission from Gorzelanny et al. [22].

\section{Corneocytes}

Keratinocytes proliferate in the basal layer of the epidermis and migrate upwards, undergoing a sequential differentiation that culminates with death by cornification [14]. Cornification is usually described by 3 main events: formation of an intracellular keratin network (with the loss of organelles); assembly of the CE with the CLE covalently attached; and selective degradation of
CDs. The maturation of the corneocytes of the SC and desquamation of superficial cells are well-controlled processes that depend on several different elements such as proteases and their inhibitors, a controlled $\mathrm{pH}$ gradient, and regulated hydration of the SC [7]. The different steps of corneocyte maturation are reflected by their morphology and surface topography as discussed below. 


\section{Morphology and Topography}

The morphology of corneocytes (Table 1; Fig. 3) was first studied in 1939 [15], which reported a diameter of approximately $25-35 \mu \mathrm{m}$ and a single-sided surface area of $700-900 \mu \mathrm{m}^{2}$, and it is of great interest in dermatology and cosmetic science since the appearance of corneocytes is increasingly associated with several skin conditions. Later, cells from the forehead and hand were observed to have the smallest surface area of $700-800 \mu \mathrm{m}^{2}$, and those from the upper arm, thigh, and axilla had the greatest surface area of 1,000-1,200 $\mu^{2}$ [16-18], which indicated that corneocytes from high proliferative regions are usually smaller [19]. An increase in the surface area of corneocytes with age has also been reported [17, 20, 21]; for example, corneocytes from the axilla have a surface area of $\sim 750 \mu \mathrm{m}^{2}$ for babies, $\sim 1,000 \mu \mathrm{m}^{2}$ for children, $\sim 1,200$ $\mu \mathrm{m}^{2}$ for adults, and, finally, $\sim 1,400 \mu \mathrm{m}^{2}$ for the elderly. Gorzelanny et al. [22] using atomic force microscopy (AFM) showed that corneocytes from aged SC (Fig. 3b) presented a surface area of $753 \pm 120 \mu \mathrm{m}^{2}$, and those from young subjects' skin (Fig. 3a), a smaller area of $555 \pm 80$ $\mu \mathrm{m}^{2}$. Moreover, the thickness of corneocytes has been reported to be inversely related to the cross-sectional area of the cells: the largest cells are usually the thinnest [23]. Furthermore, it was reported that there is a $40 \%$ decrease in thickness for corneocytes sampled from the upper SC (first tape strip), compared to those in the inner SC (20th tape strip) [20], and a corresponding increase in the surface area [24].

In the context of representing the 3D morphology of a corneocyte, a flattened Kelvin tetrakaidecahedron geometry has both a hexagonal cross-section and hexagonal upper and lower faces that are consistent with a simple 2D top-view model of the SC $[25,26]$. Close-packing of SG keratinocytes of this shape allows them to maintain an effective tight junction barrier as cells suffer cornification and move upwards to the SC. This geometry represents an optimal shape for space-filling, and those authors propose that it also represents the basis for the barrier function and physical strength of the horny layer.

\section{Mechanical Properties of Corneocytes}

The mechanical properties of corneocytes are important since the dead envelope of cells that constitute the SC must have physical properties that enable them to experience deformation in response to body movement and physical insults [27]. The skin regularly endures a range

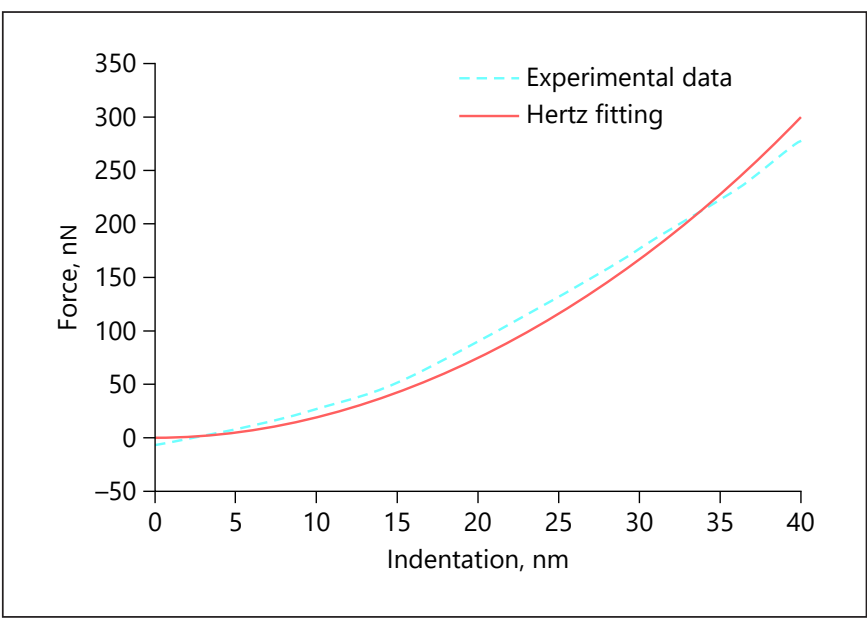

Fig. 4. Representative force as a function of indentation depth and Hertz fitting obtained on the inner forearm superficial corneocyte (2nd tape strip) at room temperature using a JPK Nanowizard instrument with a $26 \mathrm{~N} / \mathrm{m}$ stiffness cantilever with a tip radius of 50 $\mathrm{nm}$ [33].

of physical challenges, for example, walking and wearing tight shoes, wearing belts and tight clothes, and when in contact with skincare and grooming products such as shavers. The stretched or compressed SC must be able to return to its original state without structural changes. Hence, understanding the mechanical properties of single cells assists us in delineating the phenomena underlying the mechanical resistance of the skin, the maintenance of integrity, and damage processes. Corneocytes were observed to fold readily but to strongly resist elongating forces [27], and the Young's modulus was calculated to be $\sim 0.45 \mathrm{GPa}$. Later, using a micromanipulation technique, 2 populations of corneocytes were identified in normal skin based on the force required to compress the CE: resilient $(833 \pm 431 \mu \mathrm{N})$ and fragile CEs $(135 \pm 32$ $\mu \mathrm{N}$ ) [28], and a greater ratio of fragile to resilient CEs was observed in dry skin.

More recently, the mechanical properties of corneocytes have been mainly investigated using AFM to measure indentation loading curves and applying contact mechanics models, for example, Hertz-Sneddon, DMT, or JKR [29], to obtain the Young's modulus (a representative loading curve is shown in Fig. 4). There is a large variability in the Young's modulus determined for corneocytes: from 1.34 MPa up to 0.4 GPa [30-32] (Table 2). The force spectroscopy mode of AFM requires great control of the method and a rigorous analysis of the data such that the contact mechanics model and the geometry of the probe greatly influence the results. Pyramidal and conical 
Table 2. Mechanical properties of corneocytes measured by different techniques as defined by the value of the Young's modulus

\begin{tabular}{|c|c|}
\hline Methods & Young's modulus \\
\hline $\begin{array}{l}\text { Fontbrune's double micromanipulation system } \\
\text { Corneocytes dispersed in water }\end{array}$ & $450 \mathrm{MPa}[27]$ \\
\hline $\begin{array}{l}\text { Scanning probe microscopy } \\
\text { Indentation: }<10 \mathrm{~nm} \\
\text { Cantilever spring constant: - } \\
\text { Probe: spherical } \\
\text { Contact mechanics model: Hertz }\end{array}$ & $0.4 \mathrm{GPa}[32]$ \\
\hline $\begin{array}{l}\text { Treatment of skin with moisturizer for } 10 \text { days } \\
\text { Scanning probe microscopy } \\
\text { Indentation: }<10 \mathrm{~nm} \\
\text { Cantilever spring constant: } 0.1 \mathrm{~N} / \mathrm{m} \\
\text { Probe: pyramidal } \\
\text { Contact mechanics model: JKR }\end{array}$ & $\begin{array}{l}\text { Before treatment: } 50 \pm 20 \mathrm{MPa} \\
\text { After treatment: } 25 \pm 15 \mathrm{MPa}[30]\end{array}$ \\
\hline $\begin{array}{l}\text { Treatment of skin with moisturizer for } 5 \text { days } \\
\text { Scanning probe microscopy } \\
\text { Indentation: }<10 \mathrm{~nm} \\
\text { Cantilever spring constant: } 0.6 \mathrm{~N} / \mathrm{m} \\
\text { Probe: spherical } \\
\text { Contact mechanics model: JKR }\end{array}$ & $\begin{array}{l}\text { Before treatment: } 1.34 \pm 0.46 \mathrm{MPa} \\
\text { After treatment: } 1.87 \pm 0.85 \mathrm{MPa}[31]\end{array}$ \\
\hline $\begin{array}{l}\text { Scanning probe microscopy } \\
\text { Indentation: }<50 \mathrm{~nm}(\mathrm{CE}) \text { and }>50 \mathrm{~nm} \text { (cell interior) } \\
\text { Cantilever spring constant: } 35 \mathrm{~N} / \mathrm{m} \\
\text { Probe: nanoneedles (diameters of } 40 \text { and } 75 \mathrm{~nm}) \\
\text { Contact mechanics model: Oliver-Pharr }\end{array}$ & $\begin{array}{l}\text { For }<50 \mathrm{~nm}: 100 \mathrm{MPa} \\
\text { For }>50 \mathrm{~nm}: 500 \mathrm{MPa}\end{array}$ \\
\hline $\begin{array}{l}\text { Scanning probe microscopy } \\
\text { Indentation: }<50 \mathrm{~nm}(\mathrm{CE}) \text { and }>50 \mathrm{~nm} \text { (cell interior) } \\
\text { Cantilever spring constant: } 2.5 \mathrm{~N} / \mathrm{m} \\
\text { Probe: pyramidal } \\
\text { Contact mechanics model: Hertz }\end{array}$ & $\begin{array}{l}\text { Upper SC (1st tape strip): } \\
\text { For <50 nm: } 250 \mathrm{MPa} \\
\text { For }>50 \mathrm{~nm}: 300-520 \mathrm{MPa} \\
\text { Inner SC (14th tape strip): } \\
\text { For }<50 \mathrm{~nm}: 150 \mathrm{MPa} \\
\text { For }>50 \mathrm{~nm}: 250-300 \mathrm{MPa}[36]\end{array}$ \\
\hline
\end{tabular}

SC, stratum corneum; CE, cornified envelope.

probes, for example, can be regarded as spheres or paraboloids of revolution for small indentations, in which a nominal radius is usually assigned. However, for larger indentations, the probe can be treated as either a cone or pyramid with half-angles dependent on the indentation depth. Another important point to consider is the stiffness of the cantilever: if it is softer than the sample, the measured stiffness will be mainly that of the probe. We speculate that some of the probes used in the literature were too soft in this respect and resulted in Young's moduli $>1 \mathrm{GPa}$.

The influence of the different components of the cells was assessed using nanoneedles mounted on cantilevers with a spring constant of $35 \mathrm{~N} / \mathrm{m}$ [34] and the Oliver-
Pharr model [35] to fit the data. The reduced Young's modulus was calculated to be $\sim 100 \mathrm{MPa}$ for indentations $<50 \mathrm{~nm}$ and $500 \mathrm{MPa}$ at greater depths. This work can be related to that by Milani et al. [36], in which the authors calculated the apparent Young's modulus for different depths by applying the Hertz model to intervals of force as a function of indentation. Using pyramidal probes and $2.5 \mathrm{~N} / \mathrm{m}$ stiffness cantilevers, the stiffness of cells from 3 different SC depths (1st, 7th, and 14th tape strips) was measured. A decrease in the Young's modulus was established as a function of the depth of indentation. For the 1st strip, an apparent modulus of $\sim 250 \mathrm{MPa}$ for the $\mathrm{CE}$ and 300-520 MPa for the keratin bundles was calculated, while for cells deeper in the SC, a modulus of about 150 
MPa for the CE and 250-300 MPa for the keratin matrix was calculated. The increase in stiffness with proximity to the skin surface correlates with the enlargement and the thinning of cells along that axis.

However, the protocol for the collection of corneocytes might influence the results obtained. While most authors use the tape stripping method to collect cells, the influence of the tape on the compliance of the AFM force curves is not yet described. Moreover, Richter et al. [37] studied the swelling of corneocytes by AFM tapping mode (TM), using a silanization technique to firmly attach the cells to a silicon substrate. In their TM images, they did not find phase contrast differences between cells in air and the silicon substrate. However, cells in water showed a considerable phase contrast when compared to the substrate. The authors attributed this to the viscoelasticity of the swollen cells and concluded that the absence of phase contrast in the case of the cells in air was consistent with the description of corneocytes as being brittle and hard [37]. More rigorous viscoelasticity experiments, such as stress-relaxation using AFM, are nonetheless needed to confirm this assumption. In addition, it should be noted that this procedure includes an overnight drying step of the sample followed by a washing step. Because the cells are allowed to dry overnight, it is difficult to state that their mechanical properties are close to those measured when the tape stripping method is employed to collect corneocytes.

Moreover, a divergence of the mechanical properties of single cells from those obtained when cells are integrated in the SC is expected. When integrated in the tissue, corneocytes are subjected to different forces, such as interplanar and peripheral adhesion forces (explored in the following section regarding the $\mathrm{CE}$ ), which may influence their mechanical properties.

\section{Keratins: Role in Cell Mechanical Strength}

Keratins have long been recognized as the main component contributing to the mechanical strength of keratinocytes $[14,38]$. Their expression is selective and matches the degree of differentiation of cells across the epidermis. Basal keratinocytes are mitotically active and express keratins 5 and 14, with a minor amount of K15 [39]. As keratinocytes migrate upwards and suffer differentiation, they start expressing keratin 1 and 10, with a loss of K5 and K14 expression [40]. In addition, there is expression of K2 in the upper spinous and granular layers [41]. Furthermore, in the palmar-plantar epidermis, K9 is promi- nently expressed in the suprabasal differentiating layers [42]; K6, K16, K17, and K19 are also expressed in specific spatial patterns, and their expression can be rapidly induced upon various challenges, such as wounding and infection [43]. Since corneocytes are dead cells composed of a strong protein-lipid envelope surrounding these keratin bundles, studies of the isolated influence of keratin filaments on their mechanical properties are difficult to perform. Nevertheless, as seen in the previous section, it is possible to make a distinction between the contribution of the CE and the cell interior using AFM force spectroscopy. Furthermore, by studying the phenomena occurring with the viable cells of the epidermis, it is possible to extrapolate knowledge to the product of their differentiation, that is, corneocytes. For example, it has been observed in multiple studies that mutations in keratin genes, such as in the disruption of filament formation or alteration of properties and dynamics of bundle assembly, reduce the strength of cells $[44,45]$.

Living human keratinocytes were studied under loading and unloading cycles of single cells by AFM, and it was observed that a typical force of $0.4 \pm 0.1 \mu \mathrm{N}$ was required to reach $30 \%$ compression and $6.0 \pm 2.0 \mu \mathrm{N}$ for an $80 \%$ compression of the original height [44]. The Young's moduli of the keratinocyte membrane and cytoplasm were calculated to be $23-38 \mathrm{MPa}$ and $120-340 \mathrm{kPa}$, respectively, which is a factor of 25-30 greater than that of the cytoskeleton of $\mathrm{T}$ cells. This shows that keratins are responsible for the high stiffness of keratinocytes. A correlation between molecular integrity of keratin filaments (K5 and K14) and mechanical toughness of epithelial cells was also found [46]. The modulus of mutant cells (not expressing K14) was $343 \pm 18$ and $412 \pm 74 \mathrm{~Pa}$ for the nucleus and cytoplasm, respectively, while for controls, a greater cell stiffness was observed of $459 \pm 31 \mathrm{~Pa}$ for the nucleus and $752 \pm 100 \mathrm{~Pa}$ for the cytoplasm.

In a different study, Akinshina et al. [47] attempted to verify the results obtained by Jokura et al. [48]. The latter studied the effects of the natural moisturizing factor (NMF) components on the SC using nuclear magnetic resonance, rheology, and scanning electron microscopy. They observed that treating excised SC with water would release the NMF component, leading to a reduction in the mobility of keratin intermediate filaments (IFs) and a greater value of the elastic modulus. The electron micrographs suggested that, in the absence of NMF, the keratin filaments tend to associate more tightly. They concluded that the increase in corneocyte rigidity is due to increased intermolecular attractive forces between keratin filaments, and, by modelling the interactions between kera- 
tin IFs suspended in different media, found that the $\mathrm{N}$ tails of the keratin filaments act as the "glue," while the $\mathrm{C}$-tails are responsible for maintaining a certain distance between the IFs. The small charged species comprising the NMF then act in the prevention of the attractive forces between the protruding terminal domains of IF helical cores. When they are eliminated, the attractive forces are sufficiently large to "glue" the filaments together and thus increase the stiffness of the corneocyte. This denotes the complex relationships existing in SC cells in order to maintain mechanical integrity.

The stretching of cultured keratinocytes also provides an insight into the response of cells to certain types of mechanical stimuli. When normal human keratinocytes and $\mathrm{HaCat}$ cells were stretched, the expression of $\mathrm{K} 10$ was completely suppressed after $24 \mathrm{~h}$, and the K6 expression was induced; that is, the mechanical stimulus suppressed the differentiation of the cells [49]. The response of cultured cells to mechanical stimuli raises the question of what happens to keratin expression when the skin is subjected to clinically relevant pressures, such as those of a patient lying in bed or seated in a wheelchair: are keratinocytes able to adapt in the presence of mechanical loading? Using a device to periodically stimulate keratinocytes (over $80 \mathrm{~h}$ ), it was observed that the keratin distribution of the cells was amorphous and partly granular, as described for corneocytes [50]. The expression of a $67-\mathrm{kDa}$ keratin was found in mechanically stimulated HaCat cells, which is not normally expressed by cultured keratinocytes. Furthermore, Yamaguchi et al. [51] found that non-palmoplantar keratinocytes gained the ability to express $\mathrm{K} 9$ when co-cultured with palmoplantar fibroblasts.

The influence of the morphology and composition of plantar skin on the tolerance to load has been studied [52]. Plantar SC was found to be a factor of 16 thicker than the SC from non-plantar skin, with greater interdigitation between the epidermis and dermis and with a 2.1 increase in fluorescence intensity of desmoglein 1, a key component of CDs. Moreover, plantar skin was observed to deform less with loading (factors of 1.6 and 3.4 less under compression and shear, respectively). The SC showed a factor of 3 increase in the Young's modulus, and factors of 4.8 and 7.2 increase for the viable epidermis and dermis, respectively. Using a pyramidal probe, the change of the Young's modulus with depth proved to be more gradual for plantar skin (18\% decrease per $100 \mu \mathrm{m})$ than for non-plantar skin $(84 \%$ decrease per $100 \mu \mathrm{m})$. The authors suggested this may assist in mitigating stress concentrations by eliminating "hotspot" areas of stress. Plantar skin

Corneocytes: Relationship between

Structural and Biomechanical Properties seems to mitigate the effect of mechanical insults by diverse structures and mechanisms: thicker SC is associated with greater stiffness and more cohesion since there is a greater number of desmosomes. To study the mechanical properties of individual corneocytes would be a logical next step to complement the knowledge about this type of SC.

\section{Cornified Envelope}

Apart from keratin bundles that fill the interior of corneocytes, 2 other components contributing to the mechanical strength of these cells and the mechanical resistance of SC must be considered. These are the CD and the $\mathrm{CE}$. Extensive reviews on the formation and composition of both structures have been presented elsewhere $[7,8,14$, 53]. In brief, the cornification process begins with the synthesis of an immature CE beneath the plasma membrane of the keratinocytes. This envelope undergoes maturation by the covalent attachment of certain precursor proteins (such as involucrin, loricrin, and small prolinerich proteins) to produce a quite rigid structure [53]. Transglutaminase activity allows the cross-linking of proteins via $\gamma$-gamma-glutamyl- $\varepsilon$-lysine isopeptide bonds, which reinforces the envelope [54]. Some authors have observed that the composition of CEs is variable and dependent on the type of substrate available to the transglutaminases [55], with some considering the possibility of the incorporation of $\mathrm{CD}$ proteins later in the $\mathrm{CE}$ maturation [56]. In addition, the maturation of CEs culminates with the covalent attachment of ceramides, fatty acids, and others to involucrin and loricrin, creating a hydrophobic coating $[57,58]$. These bound lipids are called the CLE and are thought to be a scaffold for the intercellular lipids of the SC [59-61], further stabilizing and promoting the plasticity of this top layer.

The maturation of the CE follows the movement of corneocytes in the SC, and many authors have attempted to discriminate mature from immature CEs using microscopy and immunostaining techniques. CEs from different SC depths were first observed by Nomarski contrast microscopy, which allowed the identification of 2 different populations of CEs: "fragile" and "resilient" [55]. These 2 states of maturation can be found in the most superficial layer of SC, although the amount of fragile CE is small in normal skin and elevated in dry skin [28]. Moreover, the ratio between resilient and fragile CEs in the case of inflammatory skin disorders was found to be decreased in psoriasis and atopic dermatitis [62]. 
Most recently, the standard technique for assessing CE maturity is the double staining of lipids with Nile red and immunostaining of involucrin. Nile red is used to stain lipids covalently bound to the CE, the last step of corneocyte maturation, while immunostaining of involucrin is performed to distinguish non-matured CEs [63]. It is suggested that the loss of involucrin staining during corneocyte maturation must be a result of the covalent attachment of lipids to CE proteins, in which case the epitope of involucrin might be hidden for recognition by the antibody upon immunostaining. Corneocytes were reported to become less and less mature with increasing SC depth $[64,65]$. This morphological feature is related to the mechanical strength of corneocytes as discussed previously: a decrease in Young's modulus of corneocytes with depth from the first strip (250 MPa) to the seventh strip (150 MPa) for the CE [36] and a similar trend reported when measuring the force necessary to compress both CE types [28].

Guneri et al. [58] applied conventional methods and a novel one to evaluate the maturity of CEs. They found that the anti-involucrin and Nile red approach was limited in discriminating the maturity of CEs in the deeper SC layers of photo-exposed (PE) cheek and photo-protected (PP) post-auricular. With this method, both deep layers (PP9 and PE9, 9th tape strip) would be considered immature. Although when analysing the morphology of CEs after sonication, differences were found in the proportion of immature CEs in the deeper layers of the $\mathrm{PE}$ cheek ( $43 \pm 6.5 \%$ less maturity), but PP9 seemed to be less perturbed by this mechanical stress. This means that although the traditional method would regard PP9 CEs to be immature, they cannot be considered immature in their response to mechanical stress, suggesting that the maturation of corneocytes depends both on the formation of a mechanical resistant $\mathrm{CE}$ and on the establishment of a lipid envelope [61] surrounding the rigid CE. In summary, the maturation of CEs is intimately related to the stiffness of corneocytes: maturated corneocytes are stiffer not only because of the type of keratin bundles composing their matrix but also because of the crosslinking occurring in the CE.

\section{Corneodesmosomes}

In addition to the maturation of the CE, another important step in cornification is related to the formation and degradation of CDs. These structures are responsible for the cohesion of the deeper layers of the SC that bind the corneocytes together. The importance of these components was demonstrated by the absence of corneodesmosin expression, which results in the premature detachment of corneocytes from the SC in mice and humans [66]. The precise distribution of desmoglein 1 (DSG1) in corneocytes as they transit in SC has been studied (Fig. 5) [67]. The outer layer or mature SC is characterized by a honeycomb-like structure, in which the cornified cells are attached only laterally in the same cell layer [68]. This feature is only absent in palmar and plantar regions, where CDs are found to be dispersed over the whole surface of the cells. These junctional structures are modified desmosomes $[69,70]$ involved in desquamation, a complex process regulated by several proteases and inhibitors, first expressed in the stratum granulosum and secreted to the extracellular space. Peripheral CDs are thought to persist in the outer SC, being protected from enzymatic degradation by tight junctions that surround them [71]. A correlation between TEWL readings and the localization of DSG1 has also been established, with the presence of DSG1 on the periphery of cells being associated with a healthy SC (lower values of TEWL), and if dispersed on the whole surface, corresponding to a reduced barrier function (higher TEWL) [67]. Moreover, the honeycomb feature of mature SC seems to result in improved flexibility of the whole layer by attenuating mechanical insults, such as bending or flexing, allowing the shape of corneocytes to adapt and the outer SC to perform minimal "slide" over the inner SC [72].

Furthermore, the digestion of CDs increases with increasing relative humidity (r.h.) [73]. It was also found that at high ( $80 \%$ r.h.), but not at low (44\% r.h.), humidity, glycerol further enhances $\mathrm{CD}$ digestion. When the glycerol-treated SC was extended at $80 \%$ r.h., the extensibility of the SC increased dramatically, indicating a reduction of intercorneocyte cohesion. This behaviour is suggested to be caused by the influence of humidity on the activity of desquamatory enzymes. When an inhibitor of serine proteases was introduced, the moisture-dependent increase in tissue extensibility was prevented. Finally, the stiffness of the SC was largely unchanged even at high doses of UV radiation, while the fracture strength and fracture strain of the SC decreased with increasing UV exposure [74, 75], indicating that UV influences cellular cohesion, dominated by both intercellular lipids and CDs, while not interfering with the mechanical resistance of the tissue, which is mainly controlled by the keratin matrix and the rigid $\mathrm{CE}$ of corneocytes. A dispersion in the localization of DSG1 in the tissue, indicating degradation of CDs after UV radiation treatment, was also observed [75]. 


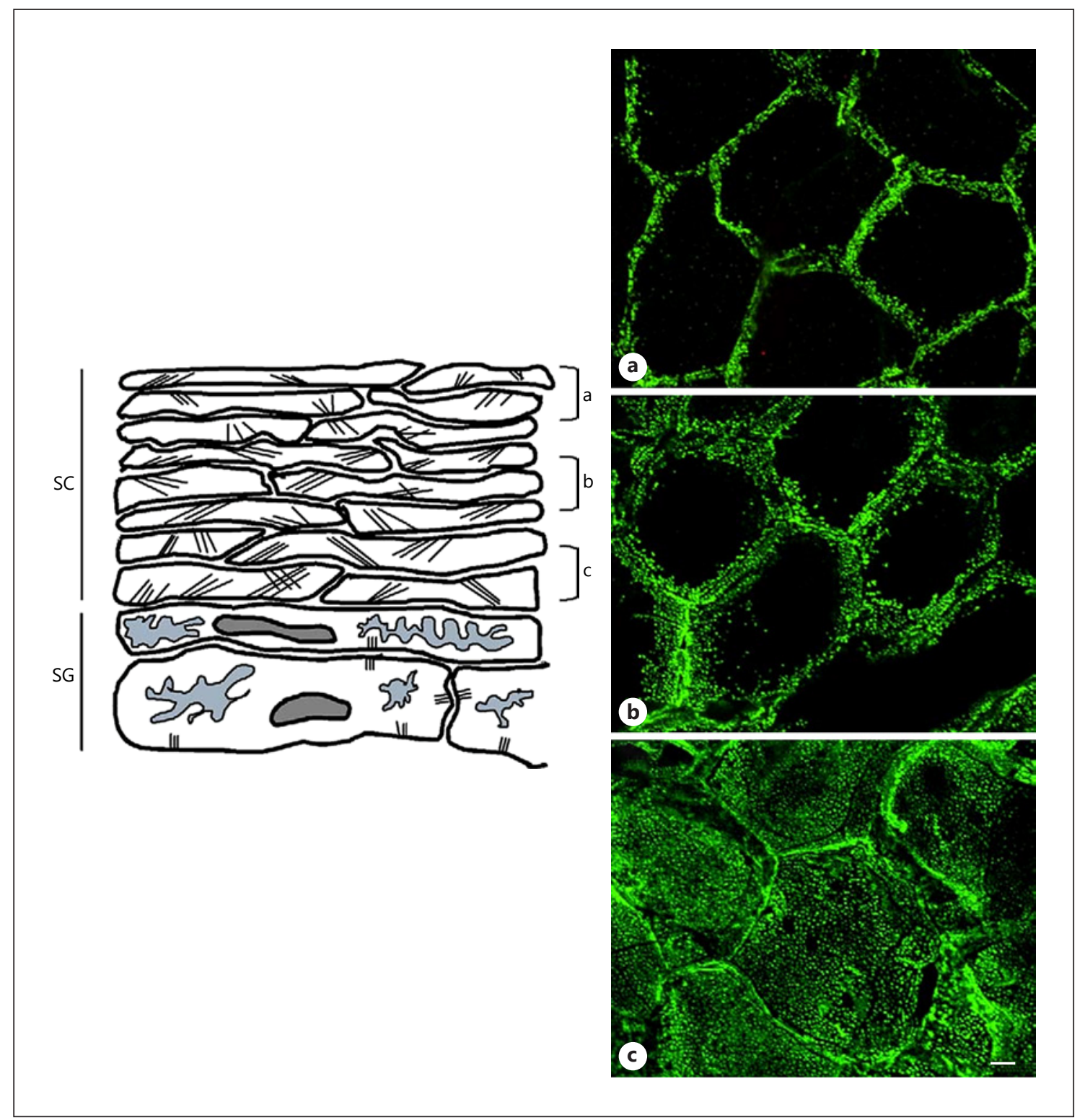

Fig. 5. Desmoglein 1 immunostaining in the SC from the inner to outer SC. Eleven tape strips were performed on the inner upper arm. In the inner SC (c), desmoglein 1 was localized over the entire surface of the corneocytes, while in the middle layer (b), it was localized mainly in the periphery, persisting in this region in the outermost layer (a). Bar, $5 \mu \mathrm{m}$. Reproduced with permission from Naoe et al. [67]. SC, stratum corneum.

CDs seem to play a major role in the cohesion of SC, which can be divided into 2 main regions: the deeperimmature SC, which is much more cohesive, and the outer SC, for which flexibility and plasticity may depend on intercellular lipids and the honeycomb localization of CDs. It is important to note that the honeycomb structure of the outer SC seems to be preferred in most body regions, but not for the palmar and plantar zones $[75,76]$.
In these regions, there prevails a strong cohesion between corneocytes, with CDs dispersed on the whole surface. This cohesiveness in combination with greater Young's modulus (greater stiffness) may be an evolutionary advantage since they are subjected to greater pressures and other forces even if it is associated with decreased suppleness and barrier function. 


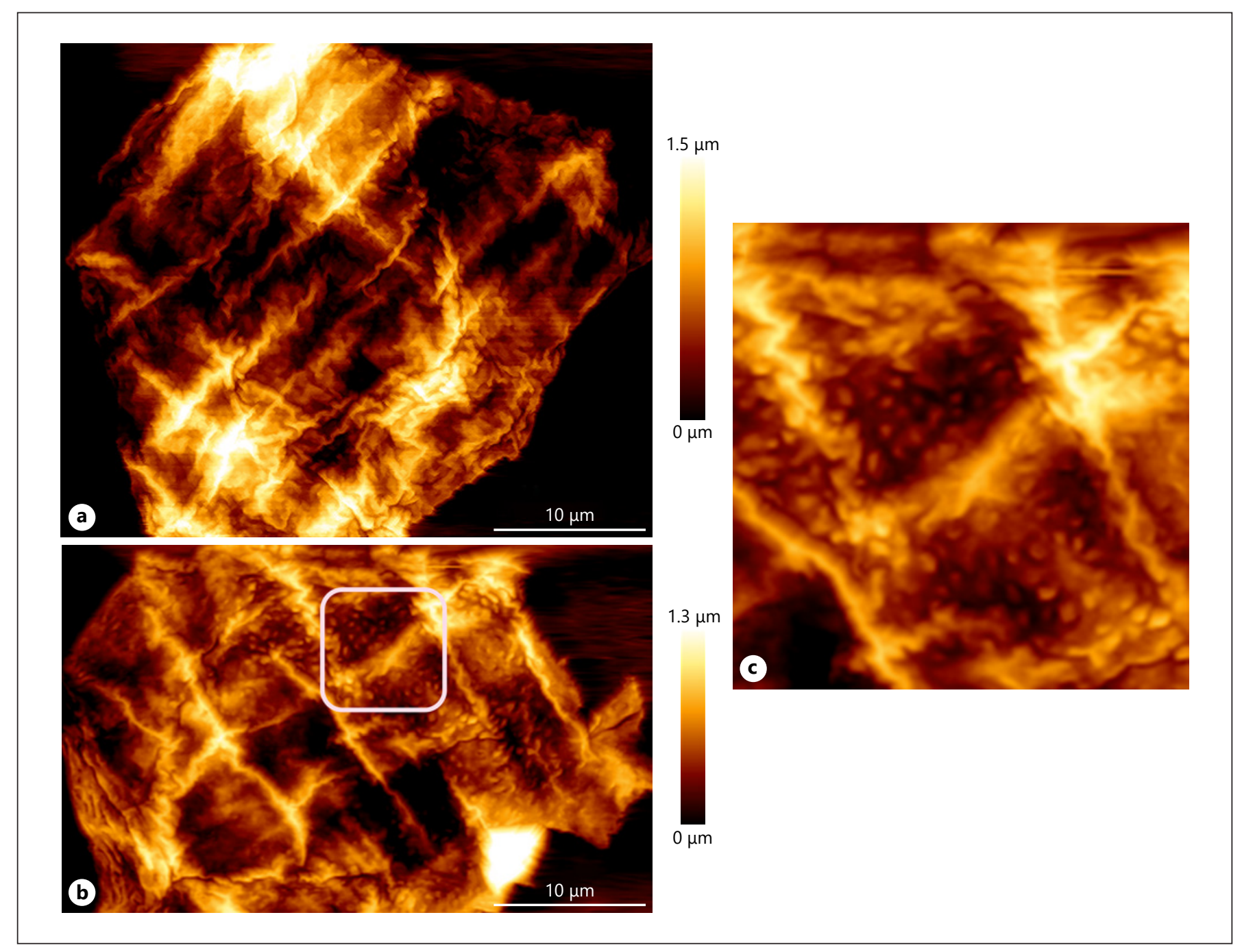

Fig. 6. AFM reveals surface topographical features on superficial corneocytes (2nd strip) from the inner forearm of 1 volunteer. Height is given in colour brightness - lateral dimension by scale bar $(10 \mu \mathrm{m})$. The images were obtained in the contact mode (cantilever stiffness of $1 \mathrm{~N} / \mathrm{m}$ and a pyramidal tip). a A smooth corneocyte presenting ridges on its surface. $\mathbf{b}$ A corneocyte presenting CNOs on its surface, highlighted by the white box. c Zoom image of (b) of CNOs present on the cell surface [33]. AFM, atomic force microscopy; CNOs, circular nanoobjects.

\section{Maturation of Corneocytes and Surface Texture}

When analysing the surface of corneocytes using SEM and AFM, small circular protrusions of a few hundreds of nanometres (termed circular nano-objects - CNOs) are observed on the basal side of the cells (Fig. 6c [33]). Cells from the palms and soles were observed to have an irregular shape, with excessive wrinkling on their surfaces and sometimes villi-like structures, while those from the axilla, umbilical region, and the back presented a hexagonal shape, with trabeculae that were parallel to the cell border, forming a regular network [77]. Similar differences were found using AFM TM to analyse the topography of cells from the forearm (smooth topography) and the palm of the hand (with the presence of numerous small protrusions) [78].

The distribution of these structures is not homogenous: some cells are covered with CNOs, while some cells are smooth with a subcellular preference of CNOs at the periphery. Such protrusions have been associated with cell-to-cell adhesion [79] and assigned to ageing [22] and some skin states and disorders $[16,22,80-82]$, as reviewed 
in detail by Riethmüller [83]. Using a computer vision algorithm, Franz et al. [84] were able to determine the mean number densities of CNOs over cell surfaces; they termed this parameter the Dermal Texture Index (DTI). It was found to be greatest on lesion areas of AD skin (DTI 200800 ), but also to be greater in non-lesion areas, when compared to healthy skin controls (DTI 100). An increase in DTI was also found in cases of loss of function of filaggrin [85]. The same authors observed corneodesmosin (a key component of CDs) to be present in CNOs by immunogold electron microscopy. Although the literature does not define a conclusive connection between CNOs and $\mathrm{CDs}$, it is reasonable to explore such relations. It is known that the degradation of filaggrin leads to an increase in NMF concentration that is responsible for water retention, which is an important factor for the activation of proteases involved in the degradation of CDs, as mentioned above. Consequently, it is reasonable to relate a mutation of the filaggrin loss-of-function gene with a greater number of CNOs by the impaired degradation of CDs when the water content is decreased. If CD degradation is impaired, corneocyte maturation might be compromised, which would explain the defect in barrier function attributed to the intercellular lipids that might not have the space to rearrange, viz., a greater number of CDs imply a greater cohesion of the SC but a loss in barrier function.

In addition, corneodesmosin was detected on the surface of the SC using the simultaneous topographic and recognition imaging (TREC) technique based on AFM [86]. The authors found the density of corneodesmosin to be about 1,000 proteins $/ \mu \mathrm{m}^{2}$ on the surface of corneocytes from superficial SC and about 1,200 in deeper layers of SC. Moreover, the size of the recognition spots was larger in the deeper SC, which is in agreement with the described progressive degradation of corneodesmosin during the desquamation process [87]. The topographic and recognition images showed that the protein is located mainly on "bead-like" structures observed by the authors, although not every structure presented recognition sites [86]. Using the same technique (TREC), Danzberger et al. [88] studied the location of glycans on the corneocyte surface. Glycan moieties were demonstrated to protect CDs from proteolysis, and so to be involved in the desquamation process [89]. In this study, almost all recognition sites for glycans were on top of "bead-like" topographical elevations (height between 1.1 and $4 \mathrm{~nm}$ ) [88]. The authors suggested that these structures could be remnants of CDs [13].

An unequivocal correlation between morphology and function of these structures is still lacking, and work to relate the above topographical feature with the mechani-

Corneocytes: Relationship between

Structural and Biomechanical Properties cal characteristics and maturation states of corneocytes should be done. A study by Guo et al. [90] carried out relevant research by exploring the adhesion of single corneocytes in different layers of the SC. Both peripheral and interplanar adhesion increased with depth. Moreover, cells from the most superficial layers showed a weaker interplanar adhesion than the peripheral one, which is consistent with the localization of CDs in the superficial SC. This anisotropy of adhesion forces agrees with the protective barrier role of the SC, allowing for a resistance to stretching and shearing forces, while not compromising the integrity of the layer.

\section{Conclusions}

Corneocytes are the "bricks" of the SC (Fig. 7) primarily responsible for the mechanical strength and stiffness and contributing to the barrier function. Being the product of differentiation of keratinocytes, these cells create distinct regions in the SC: the inner SC characterized by immature cells with a fragile $\mathrm{CE}$ and a uniform distribution of CDs, and the upper SC with resilient CEs and a honeycomb distribution of CDs.

Regarding their morphology, it is important to note the following: (1) the regional differences in the surface area and thickness ( $200 \mathrm{~nm}$ to $\leq 1 \mu \mathrm{m}$ ). Corneocytes from body sites usually more protected from chemical, physical, and mechanical insults (e.g., ventral region of arms and legs and abdomen) generally have a greater surface area $\left(1,000-1,200 \mu \mathrm{m}^{2}\right)$ and are thinner than those exposed to insults, such as the forehead, cheek, palms, and soles $\left(700-800 \mu \mathrm{m}^{2}\right)$ [91]. (2) The increase in the surface area of corneocytes with age, and finally, (3) the correlation between the surface area, thickness, and location of these cells in the SC, with upper cells presenting a greater surface area and smaller thickness than deeper cells [20, $92,93]$, which depends upon the sequential maturation of corneocytes along the SC. This morphological maturation is ultimately related to the mechanical properties of corneocytes [36], with immature cells from the deeper regions of the SC being less stiff than those at the surface $[28,36]$. Corneocytes are more rigid than other cell types (the Young's modulus of other cell types such as muscle [94] and fibroblasts [95] is typically a few $\mathrm{kPa}$ ) and present 2 distinct mechanical regions: the CE (100-250 MPa) and the keratin matrix (250-500 MPa).

The SC is usually described as having 2 different regions, the stratum compactum and the stratum disjunctum that relate to the maturation of corneocytes, particu- 


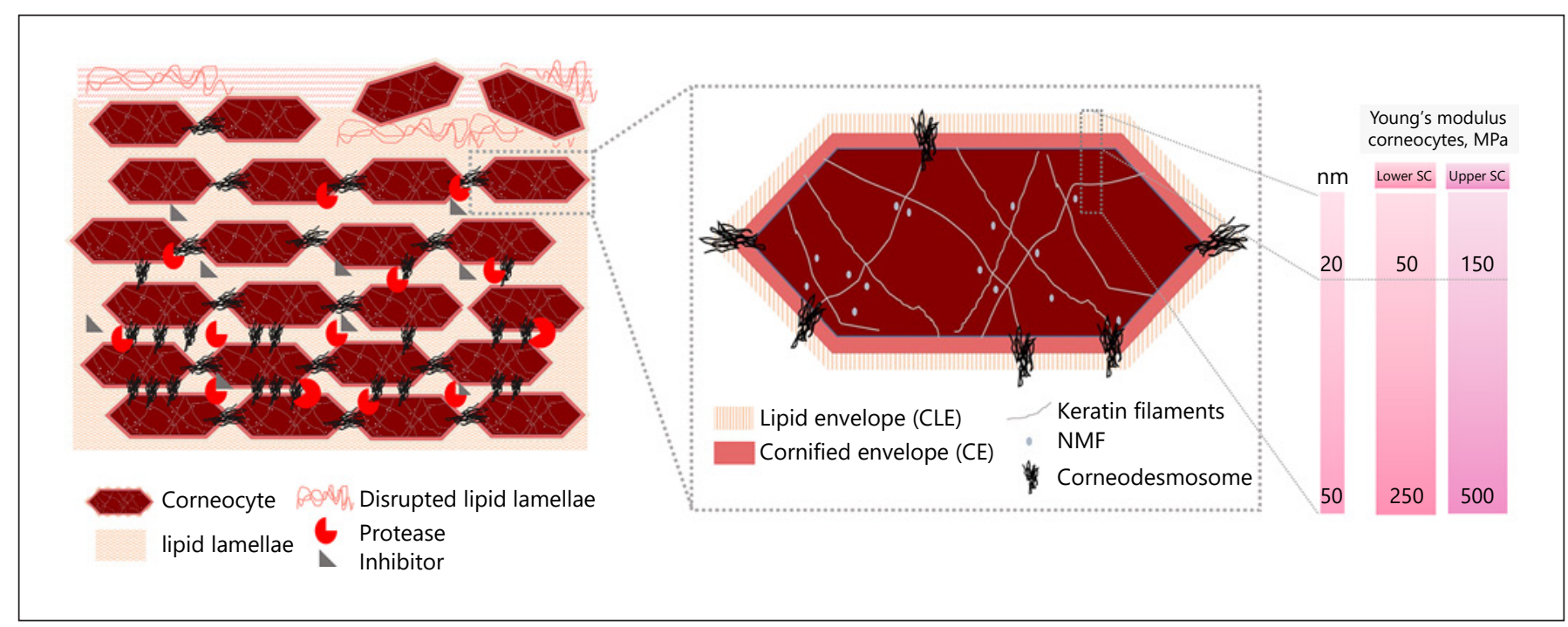

Fig. 7. "Bricks and mortar" illustration of the SC, which can be theoretically classified into 2 main zones. Deeper SC (stratum compactum) that is close to the stratum granulosum, which represents the compact SC with CDs present over the whole surface of the corneocytes. Outer SC (stratum disjunctum) with the transition to the desquamating surface, which is characterized by looser corneocytes (CDs create a honeycomb pattern). The lipid lamellae are well formed and impart some plasticity compared to the cohesive deeper SC. Moreover, the morphology and strength of the corneocytes are consistent with this classification since the inner corneocytes are softer than those at the surface. The maturation of the CE may assist in compensating for the loss of cohesion of the outer SC with a greater mechanical strength of the individual cells. SC, stratum corneum; CE, cornified envelope; CDs, corneodesmosomes; CLE, cornified lipid envelope; NMF, natural moisturizing factor.

larly in the distribution of CDs over the cell surface, as represented in Figure 5. There is a progressive degradation of CDs from the inner to the outer SC, the latter being characterized by a honeycomb structure. The presence of CNOs seems to be related to CDs, since these structures have been observed to contain corneodesmosin. However, a clear relation between their presence in normal skin and their function is still lacking. Moreover, the SC from different body sites possesses different characteristics, particularly that from palmar and plantar regions, which is much stiffer and cohesive with a uniform distribution of CDs over the surface of the cell [76]. Although the stiffness of plantar corneocytes seems to arise from the expression of $\mathrm{K} 9$, further mechanical studies are needed to comprehend the maturation of the $\mathrm{CE}$ in such regions, particularly how it is affected by the persistence of CDs in the upper SC.

To understand the morphological and mechanical properties of corneocytes is a crucial step in revealing the mechanisms underpinning skin barrier function and integrity loss. Intercellular lipids are normally considered to be the barrier function elements of the SC; however, the optimal arrangement of this "mortar" seems to de- pend on the correct formation of a cornified protein and lipid envelope that serves as a scaffold. The literature reviewed indicates that the relationship between the maturation of corneocytes and the mechanical resistance is one of the most critical steps in the formation of an effective SC barrier. When the morphology of the corneocytes is perturbed, an impaired barrier function is observed, and some skin disorders may arise. Furthermore, in the presence of water, there is increased degradation of CDs, which may compromise the response of the SC towards loading.

However, there are still gaps in the knowledge about these cells, particularly in their response to mechanical loading and frictional forces and on the role of the structural lipids attached to the CE on the desquamation process, as well as the implications of their presence on the skin microbiome. It has been suggested that the CLE may, on the one hand, function as a scaffold for the organization of the extracellular bilayers and, on the other, contribute to the cohesion of the SC [61]. Moreover, it is thought that the CLE may function as a selective body of permeation, allowing free transmembrane passage of water, while restricting the loss of larger hygroscopic mole- 
cules out of the cell, such as filaggrin breakdown products [61].

It is also relevant to mention the overlooked relationship that seems to exist between the accelerated degradation of CLE and atopic dermatitis [96]. AD is frequently aggravated by the colonization of bacteria secreting ceramidase or the activation of endogenous ceramidase activity [97], which, by contributing to the degradation of the CLE, may induce the release of hygroscopic products from the cell interior, resulting in the appearance of xerosis [98]. A recent study using AFM showed that the adhesion of Staphylococcus aureus to corneocytes from AD patients is controlled by NMF [99]. Reduced filaggrin expression, and consequently low levels of NMF, has been shown previously to facilitate the colonization by these bacteria [100]. The authors postulated that the strong adhesion of Staphylococcus aureus to the cells originates from an increased exposure or expression of ligand proteins on the SC surface. Topographic images show that the surface morphology of corneocytes from low-NMF skin samples present a high density of villous protrusions, which were the regions where strong adhesion bonds were concentrated [99]. Finally, the authors also point out that bacterium-skin adhesion is greatly enhanced by physical stress, as shown by the considerable increase in strength of adhesion bonds subjected to tensile forces [99]. Finally, it would be relevant to study the modifications imposed by pressure on the expression of keratins as well as on the maturation of the $\mathrm{CE}$, both in vitro and in vivo, and to consolidate the knowledge related to mechanical properties of corneocytes of different body sites and site-dependent cell maturation.

\section{Conflict of Interest Statement}

The authors have no conflicts of interest to declare.

\section{Funding Sources}

The work was carried out as part of the project "Skin Tissue Integrity under Shear" (STINTS) that is funded from the European Union's Horizon 2020 research and innovation programme under the Marie Skłodowska-Curie Grant Agreement No. 811965.

\section{Author Contributions}

Ana Évora wrote the original draft of the manuscript. It was edited by Simon Johnson, Zhibing Zhang, and Michael Adams.

\section{References}

1 Wong R, Geyer S, Weninger W, Guimberteau JC, Wong JK. The dynamic anatomy and patterning of skin. Exp Dermatol. 2016;25(2): 92-8.

2 Honari G, Maibach H. Chapter 1-skin structure and function. In: Maibach H, Honari G, editors. Applied dermatotoxicology. Boston: Academic Press; 2014. p. 1-10.

3 Mauldin E, Peters-Kennedy J. Chapter 6-integumentary system. In: Maxie MG, editor. Jubb Kennedy \& Palmer's pathology of domestic animals. 6th ed. W.B. Saunders; 2016 Vol. 1; p. 509-736.e1.

4 Deo PN, Deshmukh R. Pathophysiology of keratinization. J Oral Maxillofac Pathol. 2018; 22(1):86-91.

5 Talreja PS, Kasting GB, Kleene NK, Pickens WL, Wang TF. Visualization of the lipid barrier and measurement of lipid pathlength in human stratum corneum. AAPS PharmSci. 2001;3(2):E13.

6 Menon GK, Cleary GW, Lane ME. The structure and function of the stratum corneum. Int I Pharm. 2012;435(1):3-9.

7 Ishida-Yamamoto A, Igawa S. The biology and regulation of corneodesmosomes. Cell Tissue Res. 2015;360(3):477-82.

Corneocytes: Relationship between

Structural and Biomechanical Properties
8 Matsui T, Amagai M. Dissecting the formation, structure and barrier function of the stratum corneum. Int Immunol. 2015;27(6): 269-80.

9 Egawa M, Hirao T, Takahashi M. In vivo estimation of stratum corneum thickness from water concentration profiles obtained with Raman spectroscopy. Acta Derm Venereol. 2007;87(1):4-8.

10 Feingold KR, Elias PM. Role of lipids in the formation and maintenance of the cutaneous permeability barrier. Biochim Biophys Acta. 2014;1841(3):280-94.

11 Lane EB, McLean WHI. Keratins and skin disorders. J Pathol. 2004;204(4):355-66.

12 Elias PM. Stratum corneum defensive functions: an integrated view. J Invest Dermatol. 2005; 125(2): 183-200.

13 Segre JA. Epidermal barrier formation and recovery in skin disorders. J Clin Invest. 2006; 116(5):1150-8.

14 Eckhart L, Lippens S, Tschachler E, Declercq W. Cell death by cornification. Biochim Biophys Acta. 2013;1833(12):3471-80.

15 Hunter R, Pinkus H, Steele CH. Examination of the epidermis by the strip method: III. The number of keratin cells in the human epidermis. J Invest Dermatol. 1956;27(1):31-4.
16 Plewig G. Regional differences of cell sizes in the human. Stratum corneum. Part II. Effects of sex and age. J Invest Dermatol. 1970;54(1): 19-23.

17 Plewig G, Marples R. Regional differences of cell sizes in the human stratum corneum. Part I. J Invest Dermatol. 1970;54(1):13-8

18 Mohammed D, Matts PJ, Hadgraft J, Lane ME. Variation of stratum corneum biophysi$\mathrm{cal}$ and molecular properties with anatomic site. AAPS J. 2012;14(4):806-12.

19 Lee SH, Lee S. Regional and sexual differences in corneocytes among young Korean adults. Yonsei Med J. 1986;27(3):213-8.

20 Kashibuchi N, Hirai Y, O'Goshi K, Tagami H. Three-dimensional analyses of individual corneocytes with atomic force microscope: morphological changes related to age, location and to the pathologic skin conditions. Skin Res Technol. 2002;8(4):203-11.

21 Guz NV, Gaikwad RM, Dokukin ME, Sokolov I. A novel in vitro stripping method to study geometry of corneocytes with fluorescent microscopy: example of aging skin. Skin Res Technol. 2009;15(4):379-83. 
22 Gorzelanny C, Goerge T, Schnaeker E-M, Thomas K, Luger TA, Schneider SW. Atomic force microscopy as an innovative tool for nanoanalysis of native stratum corneum. Exp Dermatol. 2006;15(5):387-91.

23 Plewig G, Scheuber E, Reuter B, Waidelich W. Thickness of corneocytes. In: Marks R, Plewig G, editors. Stratum corneum. Berlin, Heidelberg: Springer; 1983. p. 171-4.

24 Gorcea M, Lane ME, Moore DJ. A proof-ofprinciple study comparing barrier function and cell morphology in face and body skin. Int J Cosmet Sci.. 2019;41(6):613-6.

25 Allen TD, Potten CS. Significance of cell shape in tissue architecture. Nature. 1976; 264(5586):545-7.

26 Feuchter D, Heisig M, Wittum G. A geometry model for the simulation of drug diffusion through the stratum corneum. Comput Visual Sci. 2006;9(2):117-30.

27 Lévêque JL, Poelman MC, de Rigal J, Kligman AM. Are corneocytes elastic? Dermatologica. 1988;176(2):65-9.

28 Harding CR, Long S, Richardson J, Rogers J, Zhang Z, Bush A, et al. The cornified cell envelope: an important marker of stratum corneum maturation in healthy and dry skin. Int J Cosmet Sci. 2003;25(4):157-67.

29 Jacobs T, Mate C, Turner K, Carpick R. Understanding the tip-sample contact: an overview of contact mechanics at the nanoscale. In: Yablon DG, editor. Scanning probe microscopy for industrial applications: nanomechanical characterization. Wiley; 2013. p. 15-48.

30 Gaikwad RM, Vasilyev SI, Datta S, Sokolov I. Atomic force microscopy characterization of corneocytes: effect of moisturizer on their topology, rigidity, and friction. Skin Res Technol. 2010;16(3):275-82.

31 Dulińska-Molak I, Lekka M, Lewandowska M, Pasikowska M, Tyszczuk B, Eris I. Preliminary studies on the characteristics of corneocytes using atomic force microscopy (AFM). Pol J Cosmet. 2012;15:50-7.

32 Luengo G, Potter A, Ghibaudo M, Baghdadli N, Enea R, Song Z. Stratum corneum biomechanics (mechanics and friction): influence of lipids and moisturizers. In: Humbert P, Fanian $\mathrm{F}$, Maibach $\mathrm{H}$, Agache $\mathrm{P}$, editors. Agache's measuring the skin; non-invasive investigations, physiology, normal constants. Cham: Springer International Publishing; 2017. p. 373-87.

33 Évora A, Zhang Z, Adams M. Forthcoming. 2021.

34 Beard JD, Guy RH, Gordeev SN. Mechanical tomography of human corneocytes with a nanoneedle. J Invest Dermatol. 2013;133(6): 1565-71.

35 Oliver WC, Pharr GM. An improved technique for determining hardness and elastic modulus using load and displacement sensing indentation experiments. J Mater Res. 2011; 7(6):1564-83

36 Milani P, Chlasta J, Abdayem R, Kezic S, Haftek M. Changes in nano-mechanical properties of human epidermal cornified cells depending on their proximity to the skin surface. J Mol Recognit. 2018;31(9):ee2722.

37 Richter T, Müller JH, Schwarz UD, Wepf R, Wiesendanger R. Investigation of the swelling of human skin cells in liquid media by tapping mode scanning force microscopy. Appl Phys A. 2001;72(1):S125-S28.

38 Norlen L. Stratum corneum keratin structure, function and formation: a comprehensive review. Int J Cosmet Sci. 2006;28(6):397-425.

39 Wang F, Zieman A, Coulombe PA. Skin keratins. Meth Enzymol. 2016;568:303-50.

40 Bragulla HH, Homberger DG. Structure and functions of keratin proteins in simple, stratified, keratinized and cornified epithelia. J Anat. 2009;214(4):516-59.

41 Collin C, Moll R, Kubicka S, Ouhayoun J-P, Franke WW. Characterization of human cytokeratin 2, an epidermal cytoskeletal protein synthesized late during differentiation. Exp Cell Res. 1992;202(1):132-41.

42 Fu DJ, Thomson C, Lunny DP, DoppingHepenstal PJ, McGrath JA, Smith FJD, et al. Keratin 9 is required for the structural integrity and terminal differentiation of the palmoplantar epidermis. J Invest Dermatol. 2014 134(3):754-63.

43 Freedberg IM, Tomic-Canic M, Komine M, Blumenberg M. Keratins and the keratinocyte activation cycle. J Invest Dermatol. 2001; 116(5):633-40.

44 Lulevich V, Yang H-Y, Isseroff RR, Liu G-Y. Single cell mechanics of keratinocyte cells. Ultramicroscopy. 2010;110(12):1435-42.

45 Knöbel M, O’Toole EA, Smith FJD. Keratins and skin disease. Cell Tissue Res. 2015;360(3): 583-9.

46 Ramms L, Fabris G, Windoffer R, Schwarz N, Springer R, Zhou C, et al. Keratins as the main component for the mechanical integrity of keratinocytes. Proc Natl Acad Sci U S A. 2013; 110(46):18513-8

47 Akinshina A, Jambon-Puillet E, Warren PB, Noro MG. Self-consistent field theory for the interactions between keratin intermediate filaments. BMC Biophys. 2013;6(1):12.

48 Jokura Y, Ishikawa S, Tokuda H, Imokawa G Molecular analysis of elastic properties of the stratum corneum by solid-state 13C-nuclear magnetic resonance spectroscopy. J Invest Dermatol. 1995;104(5):806-12.

49 Yano S, Komine M, Fujimoto M, Okochi H, Tamaki K. Mechanical stretching in vitro regulates signal transduction pathways and cellular proliferation in human epidermal keratinocytes. J Invest Dermatol. 2004;122(3): 783-90.

50 Görmar FE, Bernd A, Bereiter-Hahn J, Holzmann $\mathrm{H}$. A new model of epidermal differentiation: induction by mechanical stimulation. Arch Dermatol Res. 1990;282(1):22-32.

51 Yamaguchi Y, Itami S, Tarutani M, Hosokawa K, Miura H, Yoshikawa K. Regulation of keratin 9 in nonpalmoplantar keratinocytes by palmoplantar fibroblasts through epithelialmesenchymal interactions. J Invest Dermatol. 1999;112(4):483-8.
52 Boyle CJ, Plotczyk M, Villalta SF, Patel S, Hettiaratchy S, Masouros SD, et al. Morphology and composition play distinct and complementary roles in the tolerance of plantar skin to mechanical load. Sci Adv. 2019;5(10):eaay0244.

53 Candi E, Schmidt R, Melino G. The cornified envelope: a model of cell death in the skin. Nat Rev Mol Cell Biol. 2005;6(4):328-40.

54 Eckert RL, Sturniolo MT, Broome A-M, Ruse $\mathrm{M}$, Rorke EA. Transglutaminase function in epidermis. J Invest Dermatol. 2005;124(3): 481-92.

55 Michel S, Schmidt R, Shroot B, Reichert U. Morphological and biochemical characterization of the cornified envelopes from human epidermal keratinocytes of different origin. J Invest Dermatol. 1988;91(1):11-5.

56 Lin TK, Crumrine D, Ackerman LD, Santiago J-L, Roelandt T, Uchida Y, et al. Cellular changes that accompany shedding of human corneocytes. I Invest Dermatol. 2012;132(10):2430-9.

57 Wertz PW, Swartzendruber DC, Kitko DJ, Madison KC, Downing DT. The role of the corneocyte lipid envelopes in cohesion of the stratum corneum. J Invest Dermatol. 1989; 93(1):169-72.

58 Guneri D, Voegeli R, Gurgul SJ, Munday MR, Lane ME, Rawlings AV. A new approach to assess the effect of photodamage on corneocyte envelope maturity using combined hydrophobicity and mechanical fragility assays. Int J Cosmet Sci. 2018;40(3):207-16.

59 Nemes Z, Steinert PM. Bricks and mortar of the epidermal barrier. Exp Mol Med. 1999; 31(1):5-19.

60 López O, Cócera M, Wertz PW, López-Iglesias C, de la Maza A. New arrangement of proteins and lipids in the stratum corneum cornified envelope. Biochim Biophys Acta. 2007; 1768(3):521-9.

61 Elias PM, Gruber R, Crumrine D, Menon G, Williams ML, Wakefield JS, et al. Formation and functions of the corneocyte lipid envelope (CLE). Biochim Biophys Acta. 2014; 1841(3):314-8.

62 Hirao T, Terui T, Takeuchi I, Kobayashi H, Okada M, Takahashi M, et al. Ratio of immature cornified envelopes does not correlate with parakeratosis in inflammatory skin disorders. Exp Dermatol. 2003;12(5):591-601.

63 Hirao T, Denda M, Takahashi M. Identification of immature cornified envelopes in the barrier-impaired epidermis by characterization of their hydrophobicity and antigenicities of the components. Exp Dermatol. 2001; 10(1):35-44.

64 Mohammed D, Matts PJ, Hadgraft J, Lane ME. Depth profiling of stratum corneum biophysical and molecular properties. Br J Dermatol. 2011;164(5):957-65.

65 Richters RJH, Uzunbajakava NE, Timofeeva N, van de Kerkhof PCM, van Erp PEJ. Development of a novel approach to studying corneodesmosomes and stratum corneum adhesion: extending knowledge on the pathophysiology of sensitive skin. Skin Pharmacol Physiol. 2019;32(2):81-93. 
66 Ishida-Yamamoto A, Igawa S, Kishibe M. Order and disorder in corneocyte adhesion. Dermatol. 2011;38(7):645-54.

67 Naoe Y, Hata T, Tanigawa K, Kimura H, Masunaga $\mathrm{T}$. Bidimensional analysis of desmoglein 1 distribution on the outermost corneocytes provides the structural and functional information of the stratum corneum. J Dermatol Sci. 2010;57(3):192-8.

68 Goto H, Tada A, Ibe A, Kitajima Y. Basketweave structure in the stratum corneum is an important factor for maintaining the physiological properties of human skin as studied using reconstructed human epidermis and tape stripping of human cheek skin. Br J Dermatol. 2020;182(2):364-72.

69 Chapman SJ, Walsh A, Jackson SM, Friedmann PS. Lipids, proteins and corneocyte adhesion. Arch Dermatol Res. 1991;283(3):16773.

70 Jonca N, Leclerc EA, Caubet C, Simon M, Guerrin M, Serre G. Corneodesmosomes and corneodesmosin: from the stratum corneum cohesion to the pathophysiology of genodermatoses. Eur J Dermatol Suppl. 2011;21(Suppl 2):35-42.

71 Kitajima Y. Desmosomes and corneodesmosomes are enclosed by tight junctions at the periphery of granular cells and corneocytes, suggesting a role in generation of a peripheral distribution of corneodesmosomes in corneocytes. J Dermatol Sci. 2016;83(1):73-5.

72 Kitajima Y. Implications of normal and disordered remodeling dynamics of corneodesmosomes in stratum corneum. Dermatologica Sinica. 2015;33(2):58-63.

73 Rawlings A, Sabin R, Harding C, Watkinson A, Banks J, Ackerman C. The effect of glycerol and humidity on desmosome degradation in stratum corneum. Arch Dermatol Res. 1995;287(5):457-64.

74 Biniek K, Levi K, Dauskardt RH. Solar UV radiation reduces the barrier function of human skin. Proc Natl Acad Sci U S A. 2012;109(42): 17111-6.

75 Lipsky ZW, German GK. Ultraviolet light degrades the mechanical and structural properties of human stratum corneum. J Mech Behav Biomed Mater. 2019;100:103391.

76 Mils V, Vincent C, Croute F, Serre G. The expression of desmosomal and corneodesmosomal antigens shows specific variations during the terminal differentiation of epidermis and hair follicle epithelia. J Histochem Cytochem. 1992;40(9):1329-37.

77 Heilmann B, Ryckmanns F, Plewig G. Scanning electron microscopy of human corneocytes. In: Marks R, Plewig G, editors. Stratum corneum. Berlin, Heidelberg: Springer; 1983. p. $186-90$.
78 Fredonnet J, Gasc G, Serre G, Séverac C, Simon $M$. Topographical and nano-mechanical characterization of native corneocytes using atomic force microscopy. J Dermatol Sci. 2014;75(1):63-5.

79 Fluhr JW, Lachmann N, Baudouin C, Msika P, Darlenski R, De Belilovsky C, et al. Development and organization of human stratum corneum after birth: electron microscopy isotropy score and immunocytochemical corneocyte labelling as epidermal maturation's markers in infancy. Br J Dermatol. 2014; 171(5):978-86.

80 Koppes SA, Ljubojevic Hadzavdic S, Jakasa I, Franceschi N, Jurakić Tončić R, Marinović B, et al. Stratum corneum profiles of inflammatory mediators in patch test reactions to common contact allergens and sodium lauryl sulfate. Br J Dermatol. 2017;176(6):1533-40.

81 Engebretsen KA, Bandier J, Kezic S, Riethmüller C, Heegaard NHH, Carlsen BC, et al. Concentration of filaggrin monomers, its metabolites and corneocyte surface texture in individuals with a history of atopic dermatitis and controls. J Eur Acad Dermatol Venereol. 2018;32(5):796-804.

82 Soltanipoor M, Stilla T, Riethmüller C, Thyssen JP, Sluiter JK, Rustemeyer T, et al. Specific barrier response profiles after experimentally induced skin irritation in vivo. Contact Dermatitis. 2018;79(2):59-66.

83 Riethmüller C. Assessing the skin barrier via corneocyte morphometry. Exp Dermatol. 2018;27(8):923-30

84 Franz J, Beutel M, Gevers K, Kramer A, Thyssen JP, Kezic S, et al. Nanoscale alterations of corneocytes indicate skin disease. Skin Res Technol. 2016;22(2):174-80.

85 Riethmuller C, McAleer MA, Koppes SA, Abdayem R, Franz J, Haftek M, et al. Filaggrin breakdown products determine corneocyte conformation in patients with atopic dermatitis. J Allergy Clin Immunol. 2015;136(6) 1573-80.e2.

86 Rankl C, Zhu R, Luengo GS, Donovan M, Baghdadli N, Hinterdorfer P. Detection of corneodesmosin on the surface of stratum corneum using atomic force microscopy. Exp Dermatol. 2010;19(11):1014-9.

87 Simon M, Jonca N, Guerrin M, Haftek M, Bernard D, Caubet C, et al. Refined characterization of corneodesmosin proteolysis during terminal differentiation of human epidermis and its relationship to desquamation. J Biol Chem. 2001;276(23):20292-9.
88 Danzberger J, Donovan M, Rankl C, Zhu R Vicic S, Baltenneck C, et al. Glycan distribution and density in native skin's stratum corneum. Skin Res Technol. 2018;24(3):450-8.

89 Walsh A, Chapman SJ. Sugars protect desmosome and corneosome glycoproteins from proteolysis. Arch Dermatol Res. 1991; 283(3):174-9.

90 Guo S, Domanov Y, Donovan M, Ducos B, Pomeau Y, Gourier C, et al. Anisotropic cellular forces support mechanical integrity of the stratum corneum barrier. J Mech Behav Biomed Mater. 2019;92:11-23.

91 Marks R, Barton SP. The significance of the size and shape of corneocytes. In: Marks RPG, editor. Stratum corneum. Berlin, Heidelberg: Springer; 1983. p. 161-70.

92 Marks R, Nicholls S, King CS. Studies on isolated corneocytes. Int J Cosmet Sci. 1981; 3(6):251-9.

93 Marks R. The stratum corneum barrier: the final frontier. J Nutr. 2004;134(8 Suppl 1): 2017S-21S.

94 Collinsworth AM, Zhang S, Kraus WE, Truskey GA. Apparent elastic modulus and hysteresis of skeletal muscle cells throughout differentiation. Am J Physiol Cell Physiol. 2002;283(4):C1219-27.

95 Haga H, Sasaki S, Kawabata K, Ito E, Ushiki $\mathrm{T}$, Sambongi T. Elasticity mapping of living fibroblasts by AFM and immunofluorescence observation of the cytoskeleton. Ultramicroscopy. 2000;82(1-4):253-8.

96 Macheleidt O, Kaiser HW, Sandhoff K. Deficiency of epidermal protein-bound omegahydroxyceramides in atopic dermatitis. J Invest Dermatol. 2002;119(1):166-73.

97 Ohnishi Y, Okino N, Ito M, Imayama S. Ceramidase activity in bacterial skin flora as a possible cause of ceramide deficiency in atopic dermatitis. Clin Diagn Lab Immunol. 1999;6(1):101-4.

98 Kita K, Sueyoshi N, Okino N, Inagaki $M$, Ishida $\mathrm{H}$, Kiso $\mathrm{M}$, et al. Activation of bacterial ceramidase by anionic glycerophospholipids: possible involvement in ceramide hydrolysis on atopic skin by Pseudomonas ceramidase. Biochem J. 2002;362(3):619-26.

99 Feuillie C, Vitry P, McAleer MA, Kezic S, Irvine $\mathrm{AD}$, Geoghegan JA, et al. Adhesion of Staphylococcus aureus to corneocytes from atopic dermatitis patients is controlled by natural moisturizing factor levels. mBio. 2018;9(4):e01184-18.

100 van Drongelen V, Haisma EM, Out-Luiting JJ, Nibbering PH, El Ghalbzouri A. Reduced filaggrin expression is accompanied by increased Staphylococcus aureus colonization of epidermal skin models. Clin Exp Allergy. 2014;44(12):1515-24.
Corneocytes: Relationship between

Structural and Biomechanical Properties
Skin Pharmacol Physiol 2021;34:146-161 DOI: $10.1159 / 000513054$ 